\title{
LA REFORMA ESTATUTARIA Y LEGAL DE LOS COMISIONADOS PARLAMENTARIOS AUTONÓMICOS
}

\author{
GERARDO RUIZ-RICO RUIZ \\ Catedrático de Derecho Constitucional \\ Universidad de Jaén
}

ALBERTO ANGUITA SUSI

Profesor Titular de Derecho Constitucional

Universidad de Jaén

\author{
SUMARIO \\ I. Planteamiento. \\ II. La configuración estatutaria de los CPAs \\ (como premisa para una posterior refor- \\ ma legal). \\ III. La regulación legal de los CPAs. \\ IV. Reflexión final.
}

\section{PLANTEAMIENTO}

Si comparamos a grandes rasgos el inicial tratamiento estatutario de los Comisionados parlamentarios autonómicos (CPAs) con las actuales regulaciones surgidas tras la última oleada de reformas estatutarias, se observa fácilmente que frente a la tendencia mimética de reproducir el esquema básico de funcionamiento del Defensor del Pueblo estatal, los nuevos Estatutos han hecho un esfuerzo, con diverso resultado, por categorizar a los CPAs como instituciones de naturaleza estatuaria e instrumentos independientes de tutela de los derechos en el ámbito autonómico.

Sin embargo, conviene también precisar que las distintas reformas estatutarias operadas no han sido aprovechadas para reforzar las potestades sustantivas de los distintos CPAs; con la notable excepción del nuevo Estatuto de Cataluña ${ }^{1}$, cuya precisión normativa no ha sigo seguida paradójicamente por

1 Desde el punto de vista formal, la ubicación sistemática del Síndic de Greuges dentro del Capítulo dedicado a las Instituciones de la Comunidad refuerza sin duda su posición institucional. 
otras regulaciones estatutarias. De esta forma, los nuevos Estatutos de Autonomía han optado por lo que podría calificarse como regulación de mínimos de los distintos CPAs, una fórmula que, inevitablemente, deja en manos del legislador autonómico un amplio margen de discrecionalidad regulativa.

En este escenario, parece llegado el momento de reflexionar sobre la posible reforma legal de los CPAs, para lo cual convendría tener presente, como punto de partida, que se trata de figuras "competencialmente abiertas", cuyo mayor o menor grado de eficacia dependerá de su capacidad para utilizar aquellos instrumentos que sin estarle legalmente atribuidos tampoco le están vedados ${ }^{2}$. Este planteamiento, aparte de enfatizar las peculiaridades de los CPAs como magistraturas de persuasión, no supone defender que su actividad no deba estar regulada por un marco jurídico concreto.

Teniendo en cuenta lo anterior, el objetivo del presente trabajo es presentar algunas propuestas para reformar la Ley del Defensor del Pueblo Andaluz, en la línea seguida por la Ley 24/2009, de 23 de diciembre, del Síndic de Greuges de Cataluña.

\section{LA CONFIGURACIÓN ESTATUTARIA DE LOS CPAS (COMO PREMISA PARA UNA POSTERIOR REFORMA LEGAL)}

\section{LOS CPAS COMO GARANTES DE LOS DERECHOS ESTATUTARIOS}

Los nuevos Estatutos de Autonomía ${ }^{3}$ se han provisto de un catálogo de derechos subjetivos que derivan, en gran medida, de los derechos consa-

Desde el punto de vista material, el estatuyente ha intentado delimitar con precisión la esfera administrativa sobre la que se proyectaría la actuación del Síndic, así como el ámbito funcional que quedaría afectado por sus facultades de supervisión.

2 Vid. CARBAllo MARTÍNEZ G., "El Defensor del Pueblo y los límites de la competencia universal", Boletín de Información, Ministerio de Justicia e Interior, n. ${ }^{\circ}$ 1756, 1995.

3 Hasta el momento, han sido objeto de reforma los Estatutos de Autonomía de la Comunidad Autónoma Valenciana (Ley orgánica 1/2006, de 10 de abril), Cataluña (Ley orgánica 6/2006, de 19 de julio), Islas Baleares (Ley orgánica 1/2007, de 28 de febrero), Andalucía (Ley orgánica 2/2007, de 19 de marzo), Aragón (Ley orgánica 5/2007, de 20 de abril) y Castilla y León (Ley orgánica 14/2007, de 30 de noviembre). Por otro lado, se encuentran en fase de reforma los Estatutos de Autonomía de Extremadura y Castilla-La Mancha. Para tener una visión de conjunto sobre la influencia que las reformas estatutarias han tenido sobre los defensores del pueblo autonómicos consúltese a RUIZ-RICO RUIZ G., "Los defensores del pueblo autonómicos tras la reforma de los Estatutos de Autonomía", Revista D'Estudis Autonòmics i Federals, n. ${ }^{\circ}$ 6, 2008. Con anterioridad a las reformas estatutarias destacan los siguientes trabajos: DÍEZ BUESO L., Los Defensores del Pueblo (Ombudsmen) de las Comunidades Autónomas, Temas del Senado, Madrid, 1999; VERA PADIAL M., "Notas sobre la adaptación del Ombudsman a los ordenamientos de las Comunidades Autónomas", Autonomies. Revista Catalana de Derecho Público, n. ${ }^{\circ}$ 19, 1994; VERA SANTOS J.M., El Defensor del Pueblo en la Constitución y en los Estatutos de Autonomía, Centro de Estudios Políticos y Constitucionales-Boletín Oficial del Estado, Madrid, 2002; y AAVV., Jornadas sobre reformas estatutarias, derechos sociales y Defensores del Pueblo autonómicos, Serie Documentos, n. ${ }^{\circ}$, Servicio de Publicaciones del Defensor del Pueblo Andaluz, Sevilla, 2006. 
grados en el plano constitucional. Es más, cabe incluso considerarlos como una actualización y concreción técnico-jurídica de los derechos sociales constitucionalizados. Pero con independencia del valor jurídico y del alcance de estas declaraciones estatutarias de derechos ${ }^{4}$, cuyo análisis desbordaría el objeto de este trabajo, entendemos que frente a la mayor abstracción que presentaban las anteriores cláusulas sociales estatutarias, un catálogo de derechos estatuarios representa una concreción subjetiva de las obligaciones que corresponden a los poderes públicos autonómicos. En todo caso, estos "nuevos" derechos se presentan como el canon de referencia de los CPAs a la hora de supervisar y controlar la actuación de las distintas Administraciones públicas 5 .

\section{LOS CPAS COMO CONTROLAdORES DE LAS AdMINISTRACIONES PÚBlicAS}

Pese a que el Defensor del Pueblo estatal es el único habilitado para supervisar los tres niveles administrativos, en los nuevos Estatutos de Autonomía el ámbito de supervisión de los CPAs se ha visto ampliado más allá de la Administración autonómica y de aquellos organismos autónomos, sociedades, entidades, corporaciones y empresas que dependen de dicha Administración, gestionando servicios públicos en régimen de concesión o autorización. $\mathrm{Al}$ respecto el art. 78.1 del Estatuto de Cataluña proclamaba que el Síndic de Greuges supervisa "con carácter exclusivo" la Administración de la Generalitat y la de los organismos públicos y privados que dependen de ésta. Es decir, se consagraba en el plano estatutario la posibilidad, declarada inconstitucional por la STC 31/2010, de 28 de junio, de que esta Institución ejerciera una competencia "exclusiva", pero al mismo tiempo "excluyente", sobre el control de los órganos y entidades autonómicos.

4 Sobre este aspecto véase la STC 247/2007, de 12 de diciembre, comentada exhaustivamente, entre otros, por LÓPEZ MENUDO F., "Los derechos sociales en los Estatutos de Autonomía", Revista Andaluza de Administración Pública, n. ${ }^{\circ}$ 73, 2009. También resulta interesante consultar a FERNÁNDEZ SEGADO F. ${ }^{\circ}$, "La dinamización de los mecanismos de garantía de los derechos y de los intereses difusos en el Estado social", AAVV., Estudios de Derecho Público - Homenaje a Juan José Ruiz-Rico- (Vol. I), Tecnos, Madrid, 1997.

$5 \mathrm{El}$ art. 59.1 del Estatuto de Aragón encomienda al Justicia de Aragón «la protección y defensa de los individuales y colectivos reconocidos en este Estatutom; el art. 78.1 del Estatuto de Cataluña hace lo propio cuando atribuye al Síndic de Greuges "la función de proteger y defender los derechos y libertades reconocidos por la Constitución y el presente Estatuto"; el art. 128.1 del Estatuto de Andalucía dispone que corresponde al Defensor del Pueblo Andaluz "la defensa de los derechos y libertades comprendidos en el Título I de la Constitución y en el Título I del presente Estatuto"; y, por último, el art. 18 del Estatuto de Castilla y León afirma que el Procurador del Común actúa "para la protección y defensa de los derechos constitucionales de los ciudadanos y de los derechos y principios reconocidos en el presente Estatuto". A esto hay que unir que en los nuevos Estatutos de Autonomía los CPAs ya no figuran dentro del Título dedicado al Parlamento o al Consejo de Gobierno autonómico respectivo, sino que aparecen configurados como otros órganos de relevancia estatutaria, lo cual se puede interpretar como una forma indirecta de reforzamiento de su autonomía institucional. 
En cuanto a la supervisión de la Administración local, algunos Estatutos de Autonomía no la someten a condicionante alguno ${ }^{6}$, a diferencia de las leyes autonómicas, que siguen en este punto la STC 142/1988, de 12 de julio, según la cual la supervisión de los entes locales está condicionada a dos requisitos: que se trate de materias asumidas estatutariamente y que, además, hayan sido delegadas o transferidas por la Comunidad Autónoma respectiva al ente local supervisado?.

La delimitación funcional prevista en algunos de los nuevos Estatutos de Autonomía resulta consecuente con la "superación" de la naturaleza bifronte del régimen local. La práctica institucional de los CPAs, unido al grado de desarrollo alcanzado por el Estado de las Autonomías, permiten sostener la licitud de esa "inclinación autonómica" propugnada por algunos Estatutos de Autonomía, en los que se considera a la Administración local como parte de la organización autonómica. Dicha "integración institucional" permitiría sostener incluso la preponderancia y "exclusividad" de la intervención de los CPAs frente al Defensor del Pueblo estatal a la hora de supervisar las entidades locales.

Por lo que se refiere a la Administración periférica del Estado, en la Sentencia de referencia el Tribunal Constitucional mantuvo que si bien este ámbito no es, en sentido estricto, objeto de supervisión formal por los CPAs, éstos pueden dirigirse a dicha Administración para solicitarle la información que precisen en el desempeño de sus funciones. En la práctica esta facultad ha servido para que los órganos dependientes de aquélla resuelvan, a instancia de los Defensores autonómicos, quejas de los ciudadanos que se han visto afectados por su acción.

El art. 128.1 del Estatuto de Autonomía para Andalucía (EAA), por su parte, habilita al Defensor del Pueblo Andaluz (DPA) para «supervisar la actividad

6 El art. 18.1 del Estatuto de Castilla y León encomienda al Procurador del Común la supervisión "de la Administración de la Comunidad, la de sus entes locales y la de los diferentes organismos que de éstas dependan". En el mismo sentido, el art. 78.1 del Estatuto de Cataluña afirma que el Síndic de Greuges «también supervisa la actividad de la Administración local de Cataluña y la de los organismos públicos o privados vinculados o que dependen de la misma".

7 La mayoría de leyes autonómicas, como la Ley del Valedor del Pueblo gallego (art. 1.3), del Defensor del Pueblo navarro (art. 1.3), del Justicia aragonés (art. 2.2), del Ararteko vasco (art. 9.1 c), del Diputado del Común canario (art. 17.1), del Síndic de Greuges balear (art. 1.2), del Procurador del Común de Castilla y León (art. 1.2) y del Procurador General de Asturias (art. 13.1 c), condicionan la supervisión de la Administración local a que se trate de una materia asumida estatutariamente por la Comunidad Autónoma. Por su parte, el art. 1.2 de la Ley del Defensor del Pueblo castellano-manchego, supedita dicha supervisión a la transferencia o delegación de la materia al ente local. Para mayor abundamiento, véanse los trabajos de GARCÍA ÁLVAREZ M., "El control de la Administración local por los Comisionados parlamentarios autonómicos", AAVV., XI Jornadas de Coordinación entre Defensores del Pueblo, celebradas en León los días 25 y 26 de septiembre de 1996, Servicio de Publicaciones del Procurador del Común, León, 1997; y EMBID IRUJO A., El control de la Administración pública por los Comisionados parlamentarios autonómicos, MAP, Madrid, 1991; del mismo autor, «Los Comisionados parlamentarios autonómicos y el control de la Administración local", Revista de Estudios de la Administración Local y Autonómica, n. ${ }^{\circ} 238,1988$. 
de las Administraciones públicas de Andalucía». En virtud de esta previsión corresponde al DPA supervisar formalmente la actividad de la Administración autonómica y de los entes locales cuando actúen sobre una materia asumida estatutariamente por la Comunidad Autónoma (esfera de actuación), pero también podrá dirigirse a los órganos de la Administración central en términos de colaboración y en el desarrollo de las funciones que tiene encomendadas (esfera de influencia) ${ }^{8}$.

\section{Los nuevos ParÁmetros de tutela y CONTROL}

A la hora de supervisar al poder legislativo se abren nuevas perspectivas para los CPAs, toda vez que les corresponderá controlar la adecuación de las leyes autonómicas tanto al catálogo de derechos, tomando como base la vinculación del legislador al contenido estatutario de los mismos ${ }^{9}$, como a los objetivos y principios rectores autonómicos.

En el ámbito del poder ejecutivo, algunos estatutos de autonomía hacen referencia al desarrollo de políticas públicas, a través de las cuales se deben poner en valor el contenido de los derechos, objetivos y principios estatutarios, mediante acuerdos o consensos sociales que, más allá de su concreción legal y normativa ${ }^{10}$, requieren una serie de recursos materiales, financieros y organizativos que deberán ser sometidos a procesos externos de evaluación. En esta línea, por tanto, corresponderá a los CPAs evaluar la eficacia de dichas políticas en términos de resultado, constatando las carencias en la prestación de ciertos servicios públicos y velando por el incumplimiento de los objetivos sociales marcados.

Asimismo conviene señalar que con la introducción, en la mayoría de las nuevas previsiones estatutarias ${ }^{11}$, del derecho estatutario a una buena admi-

8 Dicho de otra forma: cuando el art. 128.1 del EAA habla de Administraciones públicas "de" Andalucía no se está refiriendo a las Administraciones públicas que operan "en" Andalucía.

$9 \mathrm{El}$ art. 78.3 del Estatuto de Autonomía de Cataluña establece al respecto: "El Síndic de Greuges puede solicitar dictamen del Consejo de Garantías Estatutarias sobre los proyectos y las proposiciones de ley sometidos a debate y aprobación del Parlamento y de los decretos leyes sometidos a convalidación del Parlamento, cuando regulan derechos reconocidos por el presente Estatuto". Por su parte, recordemos que el art. 38 del EAA afirma: «El Parlamento aprobará las correspondientes leyes de desarrollo, que respetarán, en todo caso, el contenido de los mismos (derechos) establecido por el Estatuto, y determinarán las prestaciones y servicios vinculados, en su caso, al ejercicio de estos derechos".

10 Como ha señalado AGUDO ZAMORA: "si tradicionalmente ha existido una cierta tendencia a concebir el espacio de las políticas públicas como un campo directamente vinculado al ámbito orgánico de la Administración, debe aclararse que se trata en realidad de una concepción dotada igualmente de una fuerte proyección transversal que afecta tanto a las pautas de actuación del legislador como al papel de la esfera político-gubernamental, así como al propio tejido social organizado". (Estado social y felicidad, Ed. Laberinto, Madrid, 2007, p. 154).

11 Vid. arts. 31 y 133.1 del Estatuto de Andalucía, 30 del Estatuto de Cataluña, 9 del Estatuto de la Comunidad Valenciana, 14 del Estatuto de Islas Baleares, 16 del Estatuto de Aragón y 12 del Estatuto de Castilla y León. Sobre el concepto de buena administración destacan algunos trabajos 
nistración y a la calidad de los servicios públicos se configura una versión renovada de los tradicionales principios aplicables al funcionamiento de la Administración autonómica; si bien es cierto que en la práctica los CPAs, más allá del mero control de legalidad, siempre han procurado que la actuación de las distintas Administraciones públicas se ajuste a parámetros éticos y a normas de buena conducta.

Por otra parte, en el terreno de los tribunales de justicia, la aparición de derechos estatutarios protegidos —en potencia- desde la esfera jurisdiccional ${ }^{12}$ plantea inevitablemente la cuestión de si los CPAs tendrían que funcionar como una "garantía efectiva" a la hora de reparar las vulneraciones de dichos derechos. En todo caso, la posibilidad de dotar a los CPAs de legitimación para activar los mecanismos jurisdiccionales es una opción que debería ser tomada con cierta cautela dada la naturaleza persuasiva de estas figuras. Cuestión distinta es que deban promover e impulsar la actuación de los tribunales de justicia, permitiéndoles controlar tanto el desarrollo de los procesos judiciales como la posterior ejecución de las sentencias, al objeto de garantizar una adecuada y efectiva tutela de los derechos de los ciudadanos. Es más, habría que reconocer a los CPAs la potestad, análoga a la que dispone el Defensor del Pueblo estatal en relación con los derechos fundamentales, de activar una suerte de "recurso de amparo autonómico", caso de que llegara a implantarse, o en su caso acudir a la instancia judicial que ostente una competencia especial para tutelar los derechos estatutarios.

\section{LA REGULACIÓN LEGAL DE LOS CPAS}

\section{LAS NUEVAS TENDENCIAS REGULATIVAS}

$\mathrm{Al}$ igual que sucede con las distintas previsiones estatutarias, el mimetismo es la nota más destacable entre las normas legales que regulan los CPAs. No obstante, la evolución y la práctica seguida, unido a la progresiva incorporación de nuevos CPAs, hace que pueda hablarse de una «nueva generación normativa" que ha venido a mejorar la funcionalidad y a reforzar la independencia de estas figuras. Dicha generación está representada por una serie de disposiciones (Ley 5/2005, de 16 de diciembre, del Procurador General del Principado de Asturias; Ley 6/2006, de 2 de mayo, del Defensor del Pueblo

doctrinales: COBREROS MENDAZONA E., "Nota al Código Europeo de Buena Conducta Administrativa", Revista Vasca de Administración Pública, n. ${ }^{\circ}$ 64, 2002; SÖDERMAN J., "El derecho fundamental a la buena administración", Gaceta Jurídica de la Unión Europea y de la Competencia, n. ${ }^{\circ} 214,2000$ y PONCE SOLÉ J., Deber de buena administración y derecho al procedimiento administrativo debido, Lex Nova, Valladolid, 2001.

$12 \mathrm{El}$ art. 39 del EAA afirma: "Los actos de los poderes públicos de la Comunidad que vulneren los derechos mencionados en el artículo anterior podrán ser objeto de recurso ante la jurisdicción correspondiente, de acuerdo con los procedimientos que establezcan las leyes procesales del Estado". 
Riojano; y Ley 6/2008, de 20 noviembre, del Defensor del Pueblo de la Región de Murcia, reformada por la Ley 9/2009, de 23 de noviembre) que encuentran en la Ley 24/2009, de 23 de diciembre, del Síndic de Greuges de Cataluña, su punto culminante.

Las distintas aportaciones contenidas en estas previsiones normativas constituyen, sin duda, un importante parámetro de referencia para evaluar y analizar cuál ha sido la "evolución institucional" de los CPAs en los últimos años. A efectos de sistematizar las principales aportaciones de dichas normas, se presentan a continuación los principales aspectos que afectan al funcionamiento de los CPAs y que deberían servir para plantear la futura reforma de aquellas leyes autonómicas que todavía no han sido actualizadas.

\section{a) Función y ámbito de supervisión}

La evolución regulativa de los CPAs queda patente en lo que se refiere a la caracterización de estas figuras como mecanismos de garantía y tutela de los derechos fundamentales y estatutarios, para lo cual utilizarán las estrategias más oportunas, tales como la supervisión de la administración pública ${ }^{13}$. Estas previsiones suponen un reforzamiento evidente de los CPAs como figuras cuya finalidad principal es la protección de los derechos de los ciudadanos; de esta manera su actividad va estar inevitablemente condicionada por esta función, lo que impide pensar, por ejemplo, en que puedan llevar cabo un control de la administración independiente o desvinculado de aquélla.

En esta línea destacan también un conjunto de leyes autonómicas que conceden a sus respectivos CPAs la facultad de defender el Estatuto de Autonomía y el ordenamiento jurídico autonómico frente a la actuación de los distintos poderes públicos.

El ámbito de supervisión administrativa es otro de los extremos sobre los que conviene detenerse, habida cuenta que las normas reguladoras de los CPAs se han inclinado claramente hacia la "progresiva ampliación" de dicho ámbito. De hecho, puede afirmarse que en la actualidad la práctica totalidad de los CPAs tienen como ámbito formal de supervisión la actividad de los entes locales que integran la respectiva comunidad autónoma, aunque también extienden su ámbito de influencia (no formal) a los organismos dependientes de la Administración general que tienen presencia autonómica. En cuanto a la supervisión de la Administración autonómica, se constata igualmente una tendencia legal a especificar como parte integrante de esta Admi-

13 En esta línea se sitúan claramente los arts. 1, 3 y 4 de la Ley del Síndic de Greuges de Cataluña, el art. 1.1 de la Ley del Defensor del Pueblo de la Región de Murcia y el art. 1.2 de la Ley del Defensor del Pueblo de La Rioja, a tenor del cual "Constituye la función primordial de la institución del Defensor del Pueblo Riojano salvaguardar a los ciudadanos frente a los abusos de autoridad y poder y las negligencias de la Administración pública de la Rioja”. 
nistración la actuación de los entes, organismos, empresas y autoridades al servicio de la misma ${ }^{14}$.

Otro importante aspecto que afecta a la supervisión de la administración se refiere a la cualificación de esta función, que viene determinada por dos importantes aspectos. El primero se refiere a la supervisión de la "inactividad administrativa", algo novedoso en las nuevas regulaciones legales pese a que los CPAs ya venían incidiendo en este ámbito ${ }^{15}$. El segundo es la introducción en algunas leyes de la "buena administración" como parámetro de supervisión ${ }^{16}$, lo que supone un importante salto cualitativo respecto a los clásicos principios informadores de la actuación administrativa del art. 103 CE.

\section{b) Estatuto personal del titular}

Frente a la timorata regulación contenida en las primeras leyes reguladoras de los CPAs, se ha ido avanzando en la línea de reconocer, pese a las posibles trabas competenciales en esta materia, a los titulares de las respectivas instituciones un conjunto de prerrogativas e incompatibilidades similar o equivalente al que gozan los parlamentarios autonómicos. Este estatuto específico y particular fomenta la independencia del titular, aunque no sea equiparable totalmente al de los representantes parlamentarios.

Asimismo, en las nuevas leyes autonómicas se incide en la independencia de origen del titular, al cual se le exige antes de ser elegido que haga declaración pública de bienes y actividades ${ }^{17}$, una práctica que si bien se había venido observando hasta ahora, se convierte así en uno de los requisitos legales para proceder a la elección del titular.

Otro importante aspecto que atañe al estatuto del titular es el que se refiere a las posibles causas de cese en el cargo, cuya eventual utilización de

14 En este sentido resultan paradigmáticos los arts. 13 de la Ley del Defensor del Pueblo de Murcia y de la Ley del Procurador General de Asturias.

15 El art. 46.2 d) de la Ley del Síndic de Greuges de Cataluña establece que esta Institución puede instar a las administraciones y organismos supervisados a "cumplir la actividad prestacional reclamada o mejorar su calidad, dentro de sus disponibilidades". De otro lado, el art. 47.2 afirma que «en el supuesto de que la resolución que adopte como conclusión de un procedimiento de investigación constate la existencia de inactividad o pasividad administrativa, puede ponerlo en conocimiento de la superioridad jerárquica de quien haya incurrido en la misma".

16 El art. 4 de la Ley del Síndic de Greuges de Cataluña, otorga a esta institución la competencia de "c) Velar porque las administraciones garanticen el derecho a una buena administración y el derecho a acceder en condiciones de igualdad a los servicios públicos y a los servicios económicos de interés general. d) Realizar estudios de carácter general sobre el funcionamiento de las administraciones, organismos y empresas que son objeto de su supervisión, y prestarles colaboración para la mejora de los criterios de actuación y la fijación de estándares de calidad de los servicios que prestan".

17 Arts. 11.5 de la Ley del Defensor del Pueblo de la Rioja, 3.2 de la Ley del Procurador General de Asturias, 12 de la Ley del Defensor del Pueblo de Murcia y 11.1 de la Ley del Síndic de Greuges de Cataluña. 
forma partidista puede incidir en una merma de la independencia del titular. $\mathrm{Al}$ respecto hay que señalar que las últimas previsiones legales en la materia han supuesto la introducción de importantes novedades no sólo en lo que se refiere al reforzamiento de las garantías sino también en cuanto a especificación de los motivos que pueden dar lugar al cese ${ }^{18}$.

Pero, sin duda, una de las novedades legales más importantes en cuanto al estatuto del titular se contiene en la Ley del Síndic de Greuges de Cataluña, cuyo art. 14.2 añade a los supuestos de cese las causas que pueden dar lugar a la suspensión en el ejercicio del cargo: a) Enfermedad grave que incapacite temporalmente para el ejercicio de las funciones ${ }^{19}$; b) Resolución judicial firme que imponga prisión provisional, libertad bajo fianza o procesamiento por delitos cometidos en el ejercicio de sus funciones o por cualquier otro delito doloso; y c) Instrucción de un procedimiento judicial de incapacitación o de inhabilitación para el ejercicio de los derechos políticos.

\section{c) Tramitación de las quejas}

Dentro de este apartado no se han producido novedades relevantes si bien puede apuntarse que las nuevas leyes autonómicas sobre los CPAs han ampliado las vías y los sujetos legitimados para interponer quejas, pero también los supuestos que pueden dar lugar al rechazo de las mismas, limitando de esta forma el posible "margen" de maniobra y arbitrariedad que pudiera darse en este ámbito ${ }^{20}$.

Una importante novedad, dentro del procedimiento de tramitación de las quejas, viene constituida por la obligación de colaboración que las distintas administraciones y organismos supervisados deben prestar a los CPAs; una colaboración que no sólo debe darse durante la tramitación de un expediente de queja, sino también una vez que se haya emitido la correspondiente resolución por el CPA respectivo.

18 Así por ejemplo, frente a la "notoria negligencia en el cumplimiento de los deberes del cargo", previsto en algunas regulaciones como la Ley del Sindic de Greuges, otras leyes autonómicas hablan de "incumplimiento de los deberes del cargo" (arts. 7.1 de la Ley del Defensor del Pueblo de Murcia y 6.1 de la Ley del Procurador General de Asturias), lo que se presta a menor confusión y utilización partidista.

19 Con buen criterio, el legislador catalán diferencia entre enfermedad que incapacita temporalmente, lo que considera como causa de suspensión, y enfermedad que imposibilita (indefinidamente, se entiende) para el ejercicio de funciones, que sería causa de cese.

20 Esto sucede con el rechazo de las denominadas "quejas anónimas", cuya problemática ha sido resuelta de manera solvente, por ejemplo, por el art. 34.3 de la Ley del Síndic de Greuges de Cataluña, según el cual «la identidad de las personas que formulan una queja o solicitud y la fecha de presentación deben quedar acreditadas en todos los casos, sea cual sea el medio de presentación". De la misma forma, el art. 35.1 determina que "las quejas y las solicitudes de actuación de oficio deben especificar la vulneración de derechos o libertades constitucionales o estatutarios denunciada, y deben hacer constar la identidad y el domicilio de notificaciones de las personas que las presentan". 
La configuración de los CPAs como "magistraturas de persuasión" no resulta en modo alguno incompatible, antes al contrario, con la previsión legal de medidas que redunden en la eficacia resolutiva de estas instituciones. Esto explica que la mayoría de las nuevas leyes autonómicas en la materia hagan mención al deber general de auxilio que las autoridades y organismos supervisados están obligados a observar para con los $\mathrm{CPAs}^{21}$.

Finalmente, conviene hacer una referencia a la tipología de resoluciones que pueden emitir los CPAs. En este sentido, las distintas leyes autonómicas han ido delimitando con mayor claridad cuáles son las competencias de aquéllos, lo que ha ayudado, precisamente, a definir también con un mayor grado de nitidez el contenido de dichas resoluciones. Entre dichas resoluciones destacan aquéllas que los CPAs dirigen al legislador, un aspecto de importante calado dado que trasciende el ámbito de las resoluciones administrativas, a las que el legislador autonómico siempre ha venido prestando más atención ${ }^{22}$.

\section{d) Informes}

Las últimas regulaciones legales han incidido en diversos aspectos relativos a la elaboración y presentación de los informes, tales como la tipología, el contenido mínimo de los Informes o el procedimiento de presentación de los mismos. En relación a este último aspecto, destaca el hecho de que algunas de las leyes autonómicas reguladoras de los distintos CPAs hayan fijado un plazo para evacuar los Informes anuales, un aspecto del que depende que el

21 Vid. arts. 5 y 21 de la Ley del Defensor del Pueblo Riojano, arts. 27 a 29 de la Ley del Procurador General de Asturias y arts. 10 y 27 de la Ley del Defensor del Pueblo de Murcia. En esta materia destacan, sin duda, los arts. 61.3 y 62.2 de la Ley del Síndic de Greuges de Cataluña, los cuales, en cumplimiento del mandato recogido en el art. 78.5 del Estatuto de Autonomía de Cataluña, en el que se afirma que" deben regularse por ley las sanciones y los mecanismos destinados a garantizar el cumplimiento de dicha obligación", se encargan de concretar las posibles medidas que a tal efecto puede adoptar el Síndic de cara a garantizar el cumplimiento de sus resoluciones por los organismos administrativos supervisados: a) Convocar a las personas responsables de los actos objeto de investigación para proceder a su examen conjuntamente; b) Informar de la falta de colaboración o de la obstaculización a la Comisión del Síndic de Greuges para que ésta, si lo considera oportuno, llame a comparecencia a las personas responsables de los actos objeto de investigación; c) Personarse en aquellas dependencias en las que estén custodiados los expedientes objeto de investigación para examinarlos; d) Pedir información complementaria a las administraciones, organismos, empresas y personas afectadas; e) Requerir a las administraciones, organismos, empresas y personas afectadas a cumplir ese deber; f) Presentar un informe especial ante la Comisión del Síndic de Greuges; g) Hacer públicas las sugerencias y recomendaciones efectuadas y el incumplimiento producido.

$22 \mathrm{El}$ art. 4 de la Ley del Síndic de Greuges encomienda a éste la potestad para "Sugerir o recomendar, de resultas de un procedimiento de investigación, la aprobación de una disposición normativa o la modificación de aquellas normas vigentes cuya aplicación considere que puede conducir a un resultado injusto o un perjuicio innecesarion. Una previsión que se reitera en el art. 46.2 c) de esta Ley. 
contenido de los mismos sea lo más acorde a la realidad de los hechos ${ }^{23}$. Asimismo, resulta importante destacar que se haya previsto el procedimiento para evacuar los Informes especiales o monográficos, los cuales deberán se presentados ante la Comisión correspondiente por razón de la materia por el titular o, en su caso, por el adjunto.

\section{e) Dotación económica}

Una de las más importantes manifestaciones de la independencia y autonomía de los CPAs es la económica, de ahí la importancia del proceso de elaboración y ejecución del presupuesto, pero también de la adjudicación del mismo a una determinada partida presupuestaria. En este punto, las distintas regulaciones legales adscriben el presupuesto previsto para los CPAs no a una partida más del Parlamento autonómico, sino a una partida independiente dentro del Presupuesto General de la Comunidad Autónoma ${ }^{24}$. En todo caso, el mayor "aparente grado de independencia" respecto del Parlamento no evita un mayor acercamiento a la esfera del Ejecutivo autonómico, a quien compete elaborar los presupuestos generales de la Comunidad.

\section{Propuestas de Reforma de la Ley del Defensor del Pueblo Andaluz}

La reforma de la LDPA se presenta como una tarea prioritaria, no tanto por el impacto que el nuevo EAA ha tenido sobre su perfil institucional y sus atribuciones sustantivas, sino por las perspectivas de actuación que se abren, tras la reforma estatutaria; pero, sobre todo, porque las reformas producidas hasta el momento en la legislación autonómica han supuesto una merma de la independencia y autonomía del DPA respecto a las distintas fuerzas políticas con representación parlamentaria, lo que no beneficia, precisamente, la labor de tutela de los derechos que tiene atribuida. Con el fin de sistematizar los distintos aspectos susceptibles de reforma, seguiremos en nuestra exposición la estructura de la propia LDPA.

23 El art. 64.1 de la Ley reguladora del Síndic de Greuges de Cataluña preceptúa al respecto: "El Síndic de Greuges debe presentar anualmente al Parlamento, en el plazo de treinta días a contar desde el inicio del segundo período ordinario de sesiones, un informe sobre las actuaciones de la institución". Más concreto aún se muestra el art. 30.1 de la Ley del Procurador General de Asturias, conforme al cual: "Antes del primero de abril de cada año legislativo, el Procurador General dará cuenta a la Junta General del Principado de Asturias de la gestión realizada en un informe que presentará ante la Comisión competente (...).

24 Según el art. 38.1 de la Ley del Procurador General de Asturias, éste "elaborará su proyecto de presupuesto y lo remitirá al Consejo de Gobierno a través de la Junta General del Principado de Asturias, a efectos de su incorporación como Sección independiente, al Proyecto de Ley de Presupuestos Generales del Principado". En la misma línea se sitúa el art. 87.1 de la Ley del Síndic de Greuges de Cataluña. 
a) Función y ámbito de supervisión

La caracterización estatutaria del DPA como un mecanismo de garantía y tutela de los derechos fundamentales constituye, sin duda, la referencia inexcusable a la hora de abordar el análisis de la configuración legal de esta figura. Atendiendo a ese perfil estatutario nos encontramos, sin embargo, que en la Exposición de motivos de la LDPA se establece que su función se centra en "el esclarecimiento de los actos y resoluciones de las Administraciones que integran la Comunidad Autónoma en relación con los ciudadanos a la luz de lo dispuesto en el art. 103 de la Constitución y el respeto a los derechos y libertades proclamados en el Título I". A ello se añade que el DPA "constituye un nuevo control externo sobre la Administración, ordenado tanto a la defensa de los derechos y libertades de los ciudadanos como al funcionamiento de la Administración pública».

Esta declaración, concretada en el art. 10.1 LDPA, pone de relieve, al menos desde un punto de visa teórico, que el DPA estaría habilitado para supervisar la actividad de la Administración pública sin que esté en juego la vulneración de un derecho, lo que implicaría una vuelta a la concepción clásica de esta Institución y, de paso, una clara contradicción con la letra y el espíritu del Estatuto de Autonomía. En este sentido, creemos que la protección de los derechos va a condicionar insoslayablemente la labor de supervisión de la Administración, lo cual hace difícil pensar, en la práctica, en un control administrativo desvinculado de dicha protección.

$\mathrm{Al}$ respecto, el art. 1.1 de la LDPA debería hacer mención expresa a la tutela de los derechos estatutarios, a cuyo efecto el DPA podrá supervisar la actividad de las Administraciones públicas, así como de los organismos públicos y privados vinculados o dependientes de las mismas y de las empresas que gestionan servicios públicos de forma concertada ${ }^{25}$. Pese a que en la actuali-

25 Véase el documento: “Consideraciones del Defensor del Pueblo Andaluz sobre el régimen de actuación de los entes instrumentales privados con ocasión de la aprobación de la Ley 9/2007, de 22 de octubre, de la Administración de la Junta de Andalucía" (www.defensor-and.es).

En los debates parlamentarios de elaboración de la LDPA ya salió a relucir la problemática relativa al ámbito de supervisión. Al respecto hay que recordar que el art. 1.1 del texto del proyecto de Ley afirmaba que el DPA podrá supervisar "la actividad de la Administración autonómica y local». Tras el debate parlamentario correspondiente, y pese a que en la redacción final de dicho precepto sólo se hablaba de Administración autonómica, el portavoz socialista apostillaba: «...en el bien entendido de que para nosotros Administración autonómica también comprende ahí la Administración local, en la medida en que haya transferencia o delegación". Por otro lado, el portavoz del Grupo Andalucista, Sr. Uruñuela Fernández, iba más allá cuando proponía que el ámbito de actuación del DPA no sólo debe abarcar la Administración autonómica y local, sino también la Administración central o periférica del Estado con sede en la Comunidad Andaluza. Frente a la polémica planteada, resultan ilustrativas las palabras del portavoz socialista, Sr. López y López, quien afirmaba: "pretender decir que (...) Administración autonómica es Administración en Andalucía, es pretender cambiar un adjetivo que se refiere al aspecto funcional por un aspecto territorial". Extraemos el contenido de estas intervenciones del Diario de Sesiones del Parlamento de Andalucía, n. ${ }^{\circ}$ 34, 1983. Asimismo, puede verse a CANO BUESO J., El Defensor del Pueblo Andaluz. Génesis y contenido de la Institución, Defensor del Pueblo Andaluz, Sevilla, 1986, pp. 18 a 47. 
dad el legislador hable de actividad de la Administración pública, no hay que olvidar que el DPA es competente para supervisar también la inactividad de la misma, máxime si se tiene en cuenta la importancia que la intervención activa de los poderes públicos tiene a la hora de tutelar los derechos sociales estatutarios.

En cualquier caso, a los efectos de evitar cualquier tipo de duplicidad y actuación concurrente en cuanto a la supervisión de los distintos niveles administrativos, sería necesario prever legalmente mecanismos de cooperación y coordinación (arts. 13 y 14 LDPA), como la posibilidad de firmar acuerdos o convenios bilaterales tanto con el Defensor del Pueblo como con el resto de $\mathrm{CPAs}^{26}$.

Otro importante aspecto que debería ser abordado en una futura reforma legal se refiere a los parámetros de supervisión al alcance del DPA. En este sentido sería oportuno actualizar el art. 10.1 LDPA, en el que se prevé que la supervisión de la Administración se llevará a cabo a la luz de lo dispuesto en el art. 103 CE, de conformidad con el contenido de los arts. 31 y 133 del EAA, los cuales obligan a las distintas Administraciones públicas no sólo a que actúen con arreglo a la ley sino atendiendo a una determinada ética de funcionamiento eficiente, participativo y transparente.

b) Estatuto personal del titular y de los adjuntos

En el procedimiento legal de designación del titular convendría introducir una cláusula en virtud de la cual se obligue al/los candidato/s al cargo a presentar ante la Comisión de Gobierno Interior y Derechos Humanos del Parlamento de Andalucía una declaración de bienes y actividades. La exigencia legal de este requisito, que se viene observando en la práctica parlamentaria, no sólo contribuiría a despejar cualquier duda relacionada con las incompatibilidades y la idoneidad del candidato, sino que serviría también para dotar de mayor transparencia al proceso de elección, reforzándose, de paso, la legitimidad de origen del titular.

Las causas de cese y sustitución en el cargo, por su parte, tienen una especial significación dado que trascienden el campo de la mera organización

26 La firma de acuerdos de este tipo fue introducida por el art. 2.2 de la Ley 36/1985, lo que justifica que algunas leyes autonómicas, como la aragonesa, la riojana o la catalana hayan previsto esta posibilidad. En el caso de Andalucía, el art. 24 del Reglamento de Organización y Funcionamiento del DPA se refiere a este tema. Vid. ÁLVAREZ DE MIRANDA Y TORRES F., "El marco competencial de colaboración y cooperación entre el Defensor del Pueblo y los Comisionados Autonómicos", AAVV., XIII Jornadas de Coordinación entre Defensores del Pueblo, celebradas en Canarias los días 21 a 24 de octubre de 1998, Diputado del Común de Canarias, 1999; CORECHETE MARTín M. ${ }^{a}$.J., "Propuestas de reforma de las relaciones Defensor del Pueblo-Comisionados parlamentarios autonómicos", Revista Vasca de Administración Pública, n. ${ }^{\circ}$ 56, 2000; y GARRIDO LÓPEZ C., "Fundamento y virtualidad de los acuerdos de cooperación entre el Defensor del Pueblo y los Comisionados parlamentarios autonómicos", AAVV., Derechos constitucionales y pluralidad de ordenamientos, Cedecs, Barcelona, 2001. 
institucional u orgánica para adentrarse en el ámbito de la autonomía e independencia funcional del DPA.

Por lo que a los motivos de cese respecta, el relativo a la actuación negligente del titular puede prestarse, al menos en un plano teórico o potencial, a ciertos problemas, sobre todo porque se trata de un supuesto en cuya apreciación el Parlamento, y las fuerzas políticas que lo integran, podrían poner en entredicho la independencia del DPA. Como es sabido, la relación que une al Parlamento con el DPA es de mero auxilio técnico, no de subordinación, de forma que éste no depende, fiduciariamente hablando, de la mayoría parlamentaria que lo eligió.

Frente a la notoria negligencia en el cumplimiento de las obligaciones y deberes del cargo, otras leyes autonómicas, según hemos visto, hablan de incumplimiento reiterado y grave de sus obligaciones. La concreción legal de este supuesto podría evitar peticiones infundadas de cese del titular atendiendo a razones de mera oportunidad política, de forma que el cese por negligencia deberá activarse solamente cuando el titular incumpla de manera notoria, pública y reiterada sus funciones o las ejerza de forma irresponsable.

Otro de los motivos de cese que debería ser objeto de reforma se refiere a la condena por la comisión de un delito. Si partimos de que el DPA es una magistratura de persuasión sustentando en la auctoritas del titular, cualquier circunstancia que afecte a su buen nombre debe dar lugar a la renuncia voluntaria, sin esperar a que el Parlamento se pronuncie. Es más, la existencia de una condena judicial es un título legal suficiente para que el cese del titular se produzca de forma automática, de aquí que no se entienda muy bien que el actual art. 5.2 de la LDPA establezca que el cese por la comisión de un delito doloso debe ser "decidido" por una mayoría parlamentaria de tres quintos.

Convendría asimismo reformar el sistema de sustitución previsto en los arts. 5.3 y 5.4 LDPA. En virtud del primer precepto, en el caso de expiración del mandato se mantendría al titular en el ejercicio de sus funciones en tanto no se proceda al nombramiento parlamentario de un nuevo titular o a la renovación del actual, en lugar de nombrar a un Adjunto para que lo sustituya temporalmente. Pese a lo acertado de esta previsión, el precepto que comentamos no resuelve en realidad el problema, dado que no adopta ninguna medida que obligue al Parlamento a pronunciarse sobre la reelección o el nombramiento de un nuevo titular al término del período de mandato.

En cuanto al segundo precepto citado, si el cargo de DPA quedara vacante ocupará el cargo interinamente el Adjunto que determine la Comisión de Gobierno Interior y Derechos Humanos del Parlamento de Andalucía. La introducción de este sistema de sustitución tiene su lógica si se parte de que el DPA cuenta, inexplicablemente, con cuatro Adjuntos (art. 8.1 LDPA), de ahí que el legislador no haya previsto la sustitución automática del titular por el Adjunto correspondiente atendiendo a un orden de prelación fijado pre- 
viamente, como hubiera sido deseable ${ }^{27}$, optando en cambio por dejar en manos de las fuerzas políticas con representación en la citada Comisión la capacidad para decidir cuál debe ser el Adjunto más «idóneo" para ocupar interinamente el cargo; algo que por otra parte evidencia el proceso de "subordinación política" al que se ve sometido el DPA.

En consecuencia, una de las reformas más acuciantes que convendría abordar sería la del sistema de nombramiento de los adjuntos, previsto en el art. 8.1 LDPA, cuya desafortunada redacción final, pero sobre todo su interpretación y utilización en clave política-parlamentaria, supone un flagrante atentado contra la independencia y autonomía de esta Institución. La implantación de un sistema, a través del cual las fuerzas políticas con representación parlamentaria "imponen al titular" las personas que deben ocupar el cargo de Adjunto, aparte de generar importantes disfunciones internas, constituye una buena muestra de la "politización" que acompaña la elección de ciertos $\operatorname{cargos}^{28}$, por más que el legislador se empeñe en justificar la existencia de cuatro adjuntos con el argumento, un tanto peregrino, de la necesidad de proteger a los menores (Defensor del Menor) ${ }^{29}$.

Por otra parte, la creación por vía legal de estructuras de funcionamiento rígidas, y que además responden a intereses políticos, cae por su propio peso cuando cambia el mapa político, tal y como ha sucedido en las últimas elecciones autonómicas, celebradas en marzo de 2008, en las que la Coalición Andalucista no ha logrado representación parlamentaria. En estas circunstancias habría que preguntarse si no sería conveniente implantar un sistema en el que el titular proponga y nombre libremente a uno o dos Adjuntos, como máximo, y que lo sustituyan cuando legalmente corresponda de acuerdo con un orden de prelación fijado de antemano.

Dentro del estatuto personal destaca, señaladamente, el régimen de prerrogativas e incompatibilidades. Pese a su título, el Capítulo III del Título I de la LDPA sólo se refiere al régimen de incompatibilidades del titular. Desde un punto de vista teórico y en aras de preservar la independencia del titular, parece obvio defender que el DPA goce de una serie de prerrogativas. Sin embargo, desde un punto de vista jurídico hay que recordar que la competencia

27 De hecho, el art. 10 del Reglamento de Organización y Funcionamiento del DPA dispone que el titular "cesará en el desempeño de sus funciones por las causas y en los términos establecidos en los artículos 5 y 7 de su Ley, siendo en tales supuestos sustituido en las mismas, interinamente y por su propio orden, por los Adjuntos".

28 En los debates parlamentarios de elaboración de la LDPA, el Sr. Uruñuela Fernández ya advertía que la existencia de Adjuntos no deja de ser un "sistema ideado con el fin de poder hacer juegos, juegos políticos, cuando la designación de una persona arroja determinada dificultad y se quiere dar la imagen de pluralidad y, sobre todo, se quiere llegar a pactos con determinados grupos políticos de la Cámara" (Diario de Sesiones del Parlamento de Andalucía, n. ${ }^{\circ} 34$, p. 1437).

29 BARTLETT I CASTELLÀ E.R., "Los defensores sectoriales y otras técnicas específicas utilizadas por los Comisionados parlamentarios para la defensa de los derechos constitucionales", AAVV., Jornadas sobre el Defensor del Pueblo Andaluz, Serie Documentos, n. ${ }^{\circ}$, Servicio de Publicaciones del Defensor del Pueblo Andaluz, Sevilla, 2002. 
para regular el ámbito penal y procesal corresponde, en exclusiva, al legislador estatal en virtud del art. 149.1.6 $\mathrm{CE}^{30}$.

Dado que el art. 1 de la Ley 36/1985, por la que se regulan las relaciones entre el Defensor del Pueblo y las figuras similares de ámbito autonómico, no parece la norma idónea para extender a los CPAs el sistema de prerrogativas del que gozan los parlamentarios autonómicos, entendemos que la aprobación de una ley autonómica por mayoría absoluta del Pleno del Parlamento, tal y como se prevé por el art. 108 del EAA, en cuyo ámbito de reserva material quedaría incluida la "organización de las instituciones básicas" de la Comunidad, otorgaría la suficiente y necesaria cobertura para regular las prerrogativas del DPA.

En cuanto a las incompatibilidades, destaca el notable protagonismo que el art. 7.1 LDPA concede a las de tipo político ${ }^{31}$. Es cierto que la actuación y el desempeño de las funciones que el DPA tiene encomendadas deben quedar al margen de los intereses políticos con el fin de preservar, al menos potencialmente, su independencia, pero también lo es que no sólo las "influencias políticas" pueden perturbar la recta actuación de esta Institución. Todo ello sin olvidar que las incompatibilidades no dejan de ser una ficción jurídica, cuyo fin no es otro que "aparentar" un cierto grado de independencia, pero sabiendo que el titular va a seguir comulgando con ciertos ideales.

Esta suerte de recelo hacia la actividad política resulta cuando menos paradójica en el caso andaluz, si tenemos en cuenta que el legislador autonómico se muestra — como acabamos de comprobar — "permisivo a la politización" en cuanto al sistema de designación de los Adjuntos se refiere, pese que el art. 8.2 LDPA pretenda dar a entender lo contrario ${ }^{32}$. Es decir, por un lado se exige al titular una total asepsia política desde un punto de vista funcional, mientras que orgánicamente queda sometido a los intereses políticos representados en el Parlamento.

Por otra parte, resulta igualmente contradictorio que el legislador incluya entre las causas de incompatibilidad cualquier actividad de propaganda política", desconociendo que la incompatibilidad persigue evitar una determinada clase de interferencia que en el ejercicio de un determinado cargo público puede ejercer el desarrollo paralelo o simultáneo de otra función, pero no

30 Vid. ARAGÓN REYES M., "La Ley del Procurador del Común de Castilla y León", AAVV., El Procurador del Común, Cortes de Castilla y León-Universidad de Valladolid, Valladolid, 1995, pp. 44 a 47. Esto explica que algunas leyes autonómicas reguladoras de los CPAs, como la de Canarias, Comunidad Valenciana y la Rioja, por ejemplo, regulen esta materia; mientras que otras, como la de Navarra, se muestren cautas y se remitan a la legislación vigente y al Estatuto de Autonomía. A este segundo grupo se adscribe el art. 2.1 del Reglamento de Organización y Funcionamiento del DPA.

$31 \mathrm{El}$ precepto de referencia habla de incompatibilidad con todo mandato representativo, con un cargo político o actividad de propaganda política, con la afiliación a un partido político o con el empleo activo al servicio de los mismos.

32 Recordemos que en virtud de este precepto «el Defensor del Pueblo nombrará y separará a sus Adjuntos, previa conformidad de la Comisión de Gobierno Interior y Derechos Humanos". 
afecta a la manifestación de opiniones por el titular. Por no hablar de la extraordinaria ambigüedad y ductilidad interpretativa que encierra dicha expresión, lo que puede afectar a la autonomía funcional y al ejercicio de ciertos derechos fundamentales por el titular del cargo ${ }^{33}$.

Asimismo es criticable la excesiva amplitud con la que se expresa el art. 7.1 LDPA cuando afirma que el cargo de titular es incompatible con la afiliación a cualquier asociación o fundación ${ }^{34}$. En una futura reforma legal de este precepto cabría matizar que depende del tipo de asociación o fundación de la que se trate, dado que no parece que se merme la independencia si el titular pertenece, por ejemplo, a una asociación defensora de los derechos humanos. En consecuencia, debería incluirse una cláusula legal en la que se especificara que el cargo será incompatible con la pertenencia a cualquier asociación contraria o no relacionada con los fines y funciones que corresponde desempeñar al DPA.

Tal y como puede apreciarse, el legislador andaluz se expresa en unos términos muy imprecisos a la hora de regular el régimen de las incompatibilidades. La solución prevista por el art. 7.4 LDPA, consistente en atribuir a la Comisión de Gobierno Interior y Derechos Humanos la potestad para pronunciarse sobre cualquier duda o controversia en torno a las situaciones de incompatibilidad, no parece la vía más adecuada debido a los intereses políticos representados en dicha Comisión; de ahí la conveniencia de que sea el legislador quien defina y concrete jurídicamente dichas situaciones al objeto de evitar la "utilización partidista" de las mismas.

\section{c) Tramitación de las quejas}

El art. 16.1 de la LDPA establece, entre otros requisitos, que la queja debe ser presentada por el interesado en el plazo máximo de un año, contado a partir del momento en que tuviera conocimiento de los hechos objeto de la misma, a fin de evitar que lleguen al DPA quejas desfasadas en el tiempo. No obstante, resulta paradójico que la tutela de los derechos fundamentales se someta a término, sin olvidar que el cómputo dicho plazo puede convertirse en una tarea difícil, ya que el inicio del mismo se hace depender de un parámetro de difícil prueba: el efectivo conocimiento de los

33 En consecuencia entendemos que el cargo de DPA resulta incompatible con la afiliación a un determinado partido político, pero no, por ejemplo, con la actividad de propaganda política. Otra cosa es que su posicionamiento político pueda incidir en la imagen de imparcialidad que requiere un cargo de estas características, pero ello no tiene porqué repercutir en la efectividad del ejercicio de éste. Véase como ejemplo el art. 11 de la Ley del Defensor del Pueblo de la Rioja, en el que se separa nítidamente entre las incompatibilidades (párrafo 1) y las prohibiciones inherentes al ejercicio del cargo (párrafo 2).

34 El término "afiliación" empleado por el art. 7.1 LDPA parece estar pensando, más bien, para partidos políticos o sindicatos, pero no para la "pertenencia" a asociaciones o fundaciones. En este sentido, el art. 7.1 b) de la Ley del Síndic de Greuges afirma que el cargo resulta incompatible con "la pertenencia a (...) asociaciones empresariales". 
hechos por el interesado. Es más, la fijación de un plazo para interponer la queja contradice y desvirtúa, en cierto sentido, la naturaleza y la flexibilidad que caracteriza el funcionamiento del DPA, asimilándolo a la actuación de los órganos jurisdiccionales. En este sentido, se podría adoptar como criterio alternativo el de la duración de los efectos de la vulneración de los derechos, al objeto de concretar el margen de tiempo en que se podría presentar la queja.

El art. 17.2 LDPA, por su parte, establece la obligación de no examinar las quejas que se encuentren sub-iudice, así como la suspensión de sus actuaciones cuando el contenido de una queja sea objeto de impugnación ante los tribunales. La introducción estatutaria de un catálogo de derechos plantea la necesidad de agilizar los mecanismos jurisdiccionales de tutela, tal y como prevé el art. 39 del EAA. En este sentido, el DPA podría, como viene haciéndolo, jugar un importante papel a la hora de contribuir y coadyuvar a que los órganos jurisdiccionales desempeñen correctamente dicho cometido. Por este motivo, sería necesario flexibilizar, en la línea de otras regulaciones autonómicas, los términos en los que se expresa el art. 17.2 LDPA $^{35}$.

El art. 17.3 LDPA distingue entre las quejas anónimas, que deben ser rechazadas, y otro grupo de quejas que pueden serlo. En relación a las primeras conviene matizar que pese a la regulación legal, la práctica ha venido demostrando que si bien el DPA rechaza las quejas anónimas, por motivos obvios, ello no obsta para que en ocasiones se haya iniciado una investigación de oficio partiendo del supuesto planteado en las mismas. En cuanto a las segundas, hay que señalar que las causas de rechazo no son taxativas, entre otros motivos porque en la práctica se suelen rechazar algunas quejas por otras causas no previstas legalmente ${ }^{36}$. Aunque $a$ priori parezca un tanto absurdo intentar regular normativamente este extremo, dada la flexibilidad que

35 Hay que recordar que el objetivo de este precepto no es otro que evitar duplicidades y resoluciones sustantivas contradictorias a la hora de tutelar un derecho concreto, así como evitar posibles intromisiones en el principio de independencia judicial, pero nada impide que el DPA vele, en pro de garantizar el derecho a la tutela judicial efectiva, porque la Administración de Justicia resuelva eficazmente los asuntos de su competencia. A esta idea responde la parte final del art. 17.2 LDPA cuando se afirma que "ello no impedirá, sin embargo, la investigación sobre los problemas generales planteados en las quejas presentadas. En cualquier caso velará porque la Administración Autonómica resuelva, en tiempo y forma, las peticiones y recursos que le hayan sido formulados". Por lo que respecta a la primera parte de dicho precepto, hay que tener presente la eventualidad de que se haya trasladado a la esfera jurisdiccional un problema "general" planteado ante el DPA. Por ello, habría que diferenciar si se trata de recursos individuales, que no obstan para que el Defensor pueda seguir investigando cuando exista un colectivo amplio que haya preferido agotar con carácter previo la solución del caso ante éste. Este tema ha sido estudiado, entre otros, por MAGRO SERVET V., "La delimitación competencial entre el Defensor del Pueblo, los Comisionados parlamentarios de las Comunidades Autónomas y los órganos del Poder Judicial", Revista del Poder Judicial, n. ${ }^{\circ}$ 56, 1999.

36 Pueden citarse como motivos de rechazo no previstos expresamente por el legislador: la ausencia de interés legítimo, la no utilización previa de la vía administrativa, la duplicidad en el objeto de la queja, la falta de documentos y datos necesarios para la investigación y la incompetencia del DPA, entre otros supuestos. 
rige la actuación del DPA, entendemos que de esta forma se evitaría cualquier atisbo de arbitrariedad a la hora de proteger los intereses del ciudadano que interpone la queja.

Otro de los aspectos más destacables de la tramitación de las quejas se refiere al hecho de determinar si la "obligación" de colaboración por parte de los organismos supervisados, prevista en el art. 19.1 LDPA, es aplicable sólo a los de la Administración autonómica y local, o si también se extendería a los dependientes de la Administración central, que escaparían al ámbito de supervisión formal del DPA. En principio, parece lógico pensar que los organismos integrantes de esta última administración estarían exentos del deber de colaborar, con independencia de que el DPA pudiera dirigirse a ellos con el fin de requerirles la información y los documentos oportunos a los efectos de resolver algún asunto de su competencia.

Aparte del ámbito subjetivo de aplicación, el art. 19.1 LDPA plantea asimismo el problema relativo a la naturaleza del deber de colaboración por parte de las Administraciones supervisadas. Si admitimos que el DPA funciona como una magistratura de persuasión, parece obvio defender que el legislador se estaría refiriendo a una suerte de deber moral de colaboración y no a una obligación jurídicamente exigible y sancionable en caso de incumplimiento, lo que explica que en ocasiones los órganos administrativos no atiendan, aun cuando se comprometen a ello, a los requerimientos que formula el DPA tanto en los expedientes de queja como en los Informes ${ }^{37}$. A ello se une la inexistencia de mecanismos o vías legales tendentes a controlar el efectivo cumplimiento de las resoluciones por parte las Administraciones, sin perjuicio de que en la práctica se hayan venido utilizando por el DPA distintos instrumentos para lograr dicho objetivo, como la reapertura de quejas a instancia del ciudadano.

En resumidas cuentas, el cumplimiento y el respeto de las medidas propuestas por el DPA va a depender, en primera instancia, de la voluntad y responsabilidad del órgano o autoridad administrativa afectada, pero también de la autoridad moral y del prestigio social logrado por esta Institución. A ello puede contribuir la difusión pública, como prevé el art. $23 \mathrm{LDPA}$, de aquellas actitudes entorpecedoras o no colaboradoras de las Administraciones públicas. Pero sería deseable que en una futura reforma legal se estableciera asimismo la posibilidad de hacer públicos los casos de buenas prácticas administrativas

37 El art. 502.2 del Código Penal tipifica como delito de desobediencia la obstaculización, la negación o la dilación indebida de informes a los Defensores del Pueblo cuando éstos lo solicitaren. La finalidad de esta norma no es otra que preservar, en última instancia, la operatividad y autonomía de los Defensores, sin bien es cierto que su naturaleza persuasiva convierten la posibilidad de incoar la vía penal en una posibilidad un tanto remota. Al respecto resulta ilustrativo el contenido del art. 27 de la Ley del Procurador General de Asturias. Para mayor abundamiento, GARCÍA VICENTE F., “La protección penal de la función supervisora del Defensor del Pueblo y de los Comisionados parlamentarios autonómicos", AAVV., XIII Jornadas de Coordinación entre Defensores del Pueblo, celebradas en Canarias los días 21 a 24 de octubre de 1998, Diputado del Común de Canarias, 1999. 
detectadas en la tramitación de las quejas ${ }^{38}$, ya que ello generaría un indudable "efecto pedagógico" en cuanto al comportamiento exigible a los poderes públicos en el futuro, pues no debe olvidarse que el DPA debe perseguir, además de la resolución concreta de un asunto, que los órganos supervisados no vuelvan a incidir en los mismos errores.

Como es lógico, el proceso de tramitación de las quejas acaba con la emisión de una serie de resoluciones. El art. 28.2 LDPA establece que el DPA podrá proponer la modificación de aquellas normas cuyo cumplimiento puede provocar situaciones injustas o perjudiciales para los administrados; previsión que debe ponerse en relación con el art. 26 LDPA, en virtud del cual el Comisionado Andaluz podrá dirigirse al Defensor del Pueblo estatal para interponer un recurso de inconstitucionalidad contra las disposiciones normativas emanadas tanto del Parlamento como del Consejo de Gobierno de Andalucía ${ }^{39}$.

En una futura reforma de la LDPA debería incluirse la posibilidad, prevista en otras leyes autonómicas, de que el DPA pudiera dirigirse, en primera instancia, al Gobierno o al Parlamento autonómico instándole la interposición de un recurso de inconstitucionalidad contra aquellas disposiciones del Estado o de otra Comunidad que no respeten el ámbito de competencias estatutariamente atribuido a la Comunidad Autónoma de Andalucía, y en segunda, de forma subsidiaria, al Defensor del Pueblo ${ }^{40}$. Asimismo, parece del todo punto lógico y consustancial con la configuración legal del DPA que éste pudiera dirigirse al Defensor del Pueblo a fin de instar la interposición de un recurso de amparo.

El DPA no sólo estaría habilitado para plantear la modificación de una norma sino también la elaboración de la misma ( Iniciativa legislativa indirecta o impropia"). Esta idea se refuerza, aún más si cabe, si tenemos en cuenta que el grueso de la actuación del DPA se desenvuelve en el ámbito de los derechos sociales, los cuales requieren para ser efectivos del concurso tanto del Gobierno, a través de sus potestades normativas y de la previsión de los medios financieros necesarios, como del Parlamento autonómico, mediante la elaboración de las leyes y la previsión de las prestaciones y los servicios vinculados al ejercicio de dichos derechos (arts. 38 y 40.2 del EAA) ${ }^{41}$.

38 Esta medida ha sido prevista por el art. 26.2 del Reglamento de Organización y Funcionamiento del DPA en los siguientes términos: “(...) podrá incorporar al Informe anual que debe presentar al Parlamento de Andalucía una mención específica de aquellas entidades sociales que hubieran colaborado con esta Institución y se hubieran destacado en la promoción y defensa de los derechos y libertades comprendidos en el Título Primero de la Constitución".

39 La referencia a la actuación normativa emanada del Gobierno adquiere una significación singular tras la entrada en vigor de los arts. 109 y 110 del EAA, en los que se reconoce la posibilidad de que el Consejo de Gobierno andaluz pueda dictar tanto Decretos-Legislativos como Decretos-Leyes.

40 Como se recuerda en la STC 194/2004, "no resulta exigible para la promoción de los recursos de inconstitucionalidad por las Comunidades Autónomas que dichos preceptos se refieran a supuestos que tengan materialización concreta en el momento de la promoción, bastando con que pueda tenerla y ello afecte a su acervo competencial.

41 PISARELLO G., Los derechos sociales y sus garantias, Trotta, Madrid, 2007. 
Por último, el art. 29.1 LDPA prevé una serie de medidas - recordatorios, advertencias, recomendaciones y sugerencias- pero sin definirlas legalmente. En favor de esta regulación marco cabría argüir la flexibilidad que caracteriza la actuación del DPA; sin embargo, la práctica seguida por la Institución ha puesto de relieve que en ocasiones se ha hecho un uso inadecuado, contradictorio y confuso de dichas resoluciones, de aquí la necesidad de que en un futuro se estableciera una definición legal con el objeto de lograr una aplicación más eficaz de las mismas ${ }^{42}$.

\section{d) Informes al Parlamento}

La presentación de los Informes anuales es el conducto a través del cual el DPA traslada al Parlamento el resultado de sus investigaciones. El estudio de las propuestas de reformas en torno a los Informes puede ser abordado desde una doble perspectiva.

Desde un punto de vista formal, destaca el procedimiento de presentación del Informe ante el Parlamento, aspecto sobre el que se pronuncia el art. 13 LDPA. Con arreglo a su párrafo primero, los Informes anuales deben ser presentados en el período ordinario de sesiones. Es obvio que la regulación jurídica del tempo parlamentario puede ser contraproducente, pero también lo es que la fijación legal de un intervalo legal de tiempo para la presentación podría evitar, como de hecho ha sucedido en alguna ocasión, ciertas suspicacias en torno a la intencionalidad o conveniencia de presentar el Informe en un momento dado.

El acto de presentación parlamentaria de los Informes no debería limitarse a reiterar una información que los parlamentarios conocen de antemano por diversas vías. En esta línea, sería procedente que en una eventual reforma de la LDPA se estableciera la obligatoriedad de que los distintos grupos parlamentarios presentaran propuestas e iniciativas parlamentarias, tanto de tipo político como legislativo, a raíz del contenido de los Informes y que asumieran el compromiso de su cumplimiento ${ }^{43}$. Asimismo, convendría prever algún procedimiento legal que permitiera al DPA tener conocimiento periódico, a través del Gobierno autonómico, de la aplicación efectiva del contenido de los Informes presentados. En definitiva, se trataría de conectar la labor del DPA con la función de "impulso político" que el art. 106.2 $2^{\circ}$ EAA atribuye al

42 ÁLVAREZ DE MIRANDA Y TORRES F., "Sugerencias y recomendaciones que formula el Defensor del Pueblo", Teoría y Realidad Constitucional, n. ${ }^{\circ} 2,1998$.

43 Este tipo de previsiones se han concretado, hasta el momento, en acuerdos parlamentarios. En este sentido resulta paradigmático el Acuerdo del Pleno del Congreso de los Diputados de 26 de septiembre de 1995 (Boletin Oficial del Congreso de los Diputados, n. ${ }^{\circ} 276$, de 2 de octubre de 1995), sobre los criterios de política general que desarrollará el Gobierno en consonancia con las valoraciones políticas que se desprenden del contenido del Informe anual del Defensor del Pueblo, así como las iniciativas que se van a emprender para dar cumplimiento a sus recomendaciones y sugerencias. 
Parlamento. En el marco de esta competencia el DPA estaría legitimado para sugerir criterios de actuación a la Administración, pero también reformas legales y reglamentarias, sobre todo porque el Ejecutivo dispone de la potestad para aprobar Decretos-Leyes y Decretos-Legislativos.

Otro de los aspectos que debería ser objeto de reforma se refiere a la necesidad de establecer legalmente que los Informes anuales sean directamente presentados por el titular ante el Pleno del Parlamento, y no con carácter previo ante la Comisión de Gobierno Interior y Derechos Humanos que, en todo caso, podría intervenir tras la presentación plenaria del Informe para discutir su contenido ${ }^{44}$. De esta forma se evitarían duplicidades y se pondría de relieve que la dación de cuentas que supone la presentación del Informe anual tiene lugar propiamente cuando éste se presenta ante el máximo órgano de representación del Parlamento. Por lo que respecta a los Informes especiales, entendemos que al estar referidos a un aspecto concreto de la realidad social bastaría con que los mismos fueran presentados, bien por el titular bien por el Adjunto correspondiente, ante la Comisión competente por razón de la materia ${ }^{45}$.

Desde el punto de vista material, el art. 32.1 LDPA se encarga de fijar un contenido mínimo para los Informes que, lejos de erigirse en un límite a la actuación del DPA, debe ser interpretado como la posibilidad de incluir en ellos cualesquiera actuaciones llevadas a cabo por esta Institución que puedan servir para trasladar al Parlamento una información más acabada. La introducción legal de una cláusula de habilitación en este sentido sería, por tanto, conveniente.

\section{e) Dotación económica}

La dotación económica constituye un importante elemento de cara a garantizar la independencia y autonomía del DPA, de ahí que no hayan faltado quienes defiendan que el presupuesto de esta Institución debería provenir de una partida derivada de los presupuestos generales de la Comunidad, en lugar de los previstos para el Parlamento, máxime si tenemos en cuenta la tendencia hacia la "emancipación parlamentaria" del DPA plasmada en su nueva ubicación estatutaria. Con todo, somos conscientes de los inconvenientes de esta propuesta, según señalamos en su momento, puesto que el aparente reforzamiento de la autonomía del DPA quedaría desvirtuado en la práctica, dado que la aprobación final del presupuesto depende del equipo de Gobierno de turno.

También sería procedente que en la LDPA se hiciera mención a la facultad del Defensor para elaborar y ejecutar su propio presupuesto, en la medi-

44 Vid. arts. 175.1, 2 y 3 del Reglamento del Parlamento de Andalucía y 12.1 del Reglamento de Organización y Funcionamiento del DPA.

45 Esta decisión corresponde adoptarla a la Mesa del Parlamento de Andalucía al amparo de lo previsto en el art. 175.4 del Reglamento del Parlamento de Andalucía. 
da en que se trata de dos aspectos cruciales para entender la autonomía presupuestaria y que, por tanto, meritan ser regulados en la Ley y no por el Reglamento de Organización y Funcionamiento del DPA ${ }^{46}$.

\section{REFLEXIÓN FINAL}

Frente a la tendencia mimética durante los primeros años de andadura autonómica, caracterizada por el "seguidismo" constitucional, se ha pasado a una situación, tras las últimas reformas estatutarias y legales, en la que el reforzamiento de la "posición institucional" de los CPAs en el entramado autonómico es una evidente realidad, concretada en una mayor independencia y autonomía estatutaria, en una "ampliación" de sus respectivas esferas de control e influencia, así como en su configuración como auténticas instancias de tutela y garantía de los derechos.

En el caso concreto del DPA, si comparamos la actual regulación estatutaria con la anterior se aprecian, indudablemente, algunos avances. Desde un punto de vista sistemático, el nuevo art. 128 EAA queda ubicado dentro de un capítulo dedicado a otras instituciones de autogobierno, a diferencia del anterior art. 46, incardinado en el capítulo relativo al Consejo de Gobierno y al Presidente de la Junta de Andalucía. Desde una perspectiva sustantiva, las novedades se refieren a la consagración del DPA como una instancia protectora de los derechos constitucionales y estatutarios (arts. 41EAA) para lo cual supervisa el conjunto de administraciones públicas; cuando el art. 46 hablaba tan solo de la tutela de los derechos constitucionales y del control de la Administración autonómica.

Es cierto que, pese a lo dicho, las últimas reformas estatutarias no han supuesto un cambio sustantivo en cuanto a la configuración de los CPAs, pero también lo es que las posibilidades de actuación de estas figuras se ven incrementadas por el "nuevo escenario autonómico" que dichas reformas han introducido. Precisamente, esta coyuntura debe servir para plantear una reforma legal del DPA que sirva para alcanzar los siguientes objetivos: a) Una mayor eficacia en la tutela de los derechos estatutarios; b) Una efectiva supervisión de las distintas Administraciones públicas; c) La plena autonomía del DPA a la hora de desempeñar sus competencias; y d) La garantía del cumplimiento práctico de sus resoluciones y propuestas.

La reforma legal de estos aspectos propiciaría una tutela más objetiva, cercana y eficaz de los problemas que afectan a los ciudadanos, si bien la consecución de este objetivo dependerá también tanto de la pericia del DPA, a la hora de poner en práctica los medios y las competencias que les ofrece su ley reguladora, como del grado de colaboración e implicación que muestren los poderes públicos y los organismos supervisados.

46 Vid. arts. 11 y 32 a 36. 
TitLE: The statutory and legal reform of the parliamentary autonomous commissioners.

ABSTRACT: Compared to the initial trend to mimetically recreate the basic scheme of functions of the State's Ombudsman, the new Statutes of autonomy have made efforts, that lead to different results by categorizing the autonomical Ombudsman as institutions of statuary nature and independent instruments of guardianship of rights. However, these Statutes of autonomy have chosen a minimal regulation which, inevitably, left in the hands of the regional legislator, a wide margin of discretion to regulate the autonomical Ombudsman. Precisely, this situation should serve to raise a legal reform of the Andalusian Ombudsman to achieve a more effective, objective and nearby protection related to the problems affecting citizens.

SuMARIO: Frente a la inicial tendencia a reproducir miméticamente el esquema básico de funcionamiento del Defensor del Pueblo estatal, los nuevos Estatutos de Autonomia han hecho un esfuerzo, con diverso resultado, por categorizar a los Comisionados parlamentarios como instituciones de naturaleza estatuaria e instrumentos independientes de tutela de los derechos. No obstante, dichos Estatutos de Autonomia han optado por una regulación de mínimos, lo que, inevitablemente, deja en manos del legislador autonómico un amplio margen de discrecionalidad para regular los Comisionados parlamentarios autonómicos. Precisamente, esta coyuntura debe servir para plantear una reforma legal del Defensor del Pueblo Andaluz que sirva para alcanzar una tutela más objetiva, cercana y eficaz de los problemas que afectan a los ciudadanos.

KeY wORDS: Ombusdman. Statutes of autonomy. Regulatory law. Field monitoring and guardianship of the rights.

Palabras Clave: Defensores del Pueblo. Estatutos de Autonomía. Leyes reguladoras. Ámbito de supervisión y tutela de los derechos.

FECHA DE RECEPCIÓN: 03.05.2010. FeCHA DE ACEPTACIÓN: 28.07.2010. 